CONF $-960944--14$

UCRL-JC-125084

Preprint

\title{
Progress on Radio Frequency Auxiliary Heating System Designs in ITER
}

\author{
M. Makowski, G. Bosia, and F. Elio and the Home Teams \\ ITER Joint Work Site
}

This paper was prepared for submittal to 19th Symposium on Fusion Technology (SOFT), Lisbon, Portugal,

September 16-20, 1996

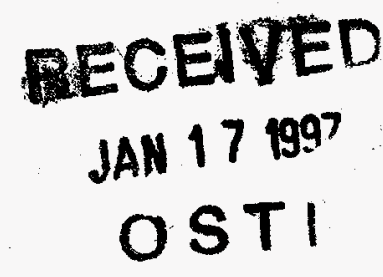

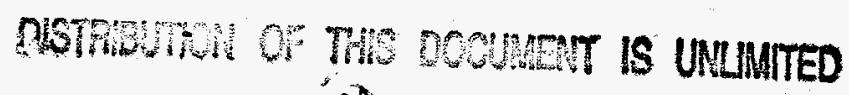

September 12, 1996

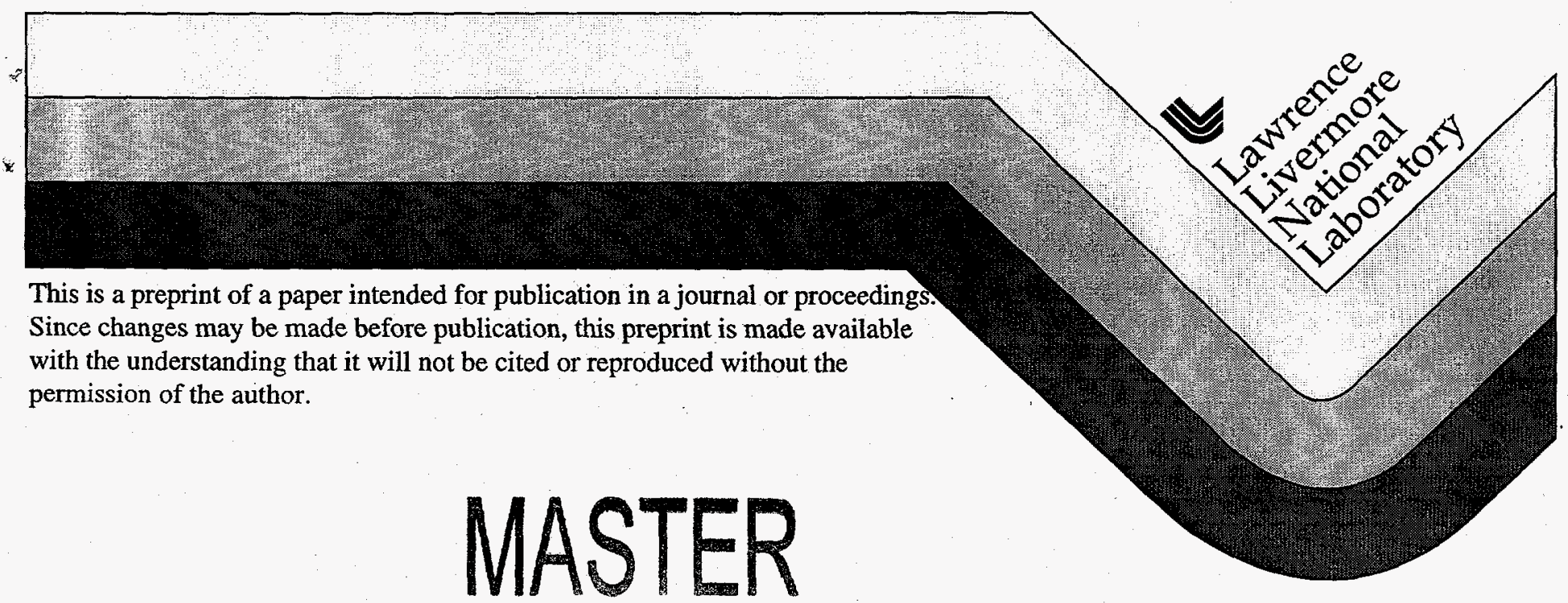




\section{DISCLAIMER}

This document was prepared as an account of work sponsored by an agency of the United States Government. Neither the United States Government nor the University of California nor any of their employees, makes any warranty, express or implied, or assumes any legal liability or responsibility for the accuracy, completeness, or usefulness of any information, apparatus, product, or process disclosed, or represents that its use would not infringe privately owned rights. Reference herein to any specific commercial product, process, or service by trade name, trademark, manufacturer, or otherwise, does not necessarily constitute or imply its endorsement, recommendation, or favoring by the United States Government or the University of California. The views and opinions of authors expressed herein do not necessarily state or reflect those of the United States Government or the University of California, and shall not be used for advertising or product endorsement purposes. 


\section{DISCLAIMER}

Portions of this document may be illegible in electronic image products. Images are produced from the best available original document. 


\title{
Progress on Radio Frequency Auxiliary Heating System Designs in ITER
}

\author{
M. Makowski, G. Bosia, and F. Elio and the Home Teams \\ ITER Joint Work Site, \\ Boltzmannstraße 2, D-85748 Garching bei München, Germany
}

ITER will require over $100 \mathrm{MW}$ of auxiliary power for heating, on- and off-axis current drive, accessing the H-mode, and plasma shut-down. The Electron Cyclotron Range of Frequencies (ECRF) and Ion Cyclotron Range of Frequencies (ICRF) are two forms of Radio Frequency (RF) auxiliary power being developed for these applications. Design concepts for both the ECRF and ICRF systems are presented, key features and critical design issues are discussed, and projected performances outlined.

\section{INTRODUCTION}

Since the initiation of the EDA phase of ITER both the ECRF and ICRF designs have evolved in parallel with the design of the basic tokamak. The designs have advanced in order to conform to the ever increasing number of design requirements and constraints. The ECRF system has evolved from a completely optical injection system to one using waveguide transmission within the port and optical injection near the blanket. Similarly, the ICRF system design has progressed from an inblanket to a fully in-port design.

\section{ECRF SYSTEM}

\subsection{ECRF Functional Capabilities}

Modeling has shown that heating and current drive with ECRF can be accomplished over a wide range of central magnetic fields, spanning 4.0 - 5.7 T, using fixed frequency, 170 $\mathrm{GHz}$, sources if the toroidal injection angle of the power can be adjusted over a $-30^{\circ}$ range. Current profile controi is also possible using the same angular steering range.

An on-axis current drive effici-ency of $\eta$ $0.30 \times 10^{20} \mathrm{~A} / \mathrm{W}-\mathrm{m}^{2}$ is predicted. Off-axis current drive is also possible with an efficiency in the range $\eta \sim 0.15-0.20 \times 10^{20} \mathrm{~A} / \mathrm{W}-\mathrm{m}^{2}$. Recent calculations have shown that with localized deposition, stabilization of $\mathrm{m}=2$ neo-classical islands is possible.

In addition to the main functions of heating and current drive, the ECRF system will also be used for start-up and wall conditioning.

\subsection{ECRF Design Features}

A total of $50 \mathrm{MW}$ of $170 \mathrm{GHz}$ power for heating and current drive is delivered to the plasma with an array of 60 waveguides divided equally between two ports. Using the full capacity of both ports an upgrade of the system to a total of $94 \mathrm{MW}$ is possible, $6 \mathrm{MW}$ of which is dedicated to the start-up and wall conditioning (SU\&WC) system. All systems are designed for steady-state operation.

Waveguide is used to transmit the millimeter wave power through the equatorial port up to the back plate. Allowance must be made for the relative motion of the vacuum vessel with respect to the cryostat. Radial motion is compensated for through the use of a bellows section between the vacuum vessel and the cryostat. Compensation for the transverse motion is accomplished by allowing an unconstrained length of waveguide to elastically distort between two fixed ends, one rigidly attached to the vacuum vessel and the other rigidly attached to the cryostat. The resulting mode conversion can be minimized through proper choice of the length and diameter of the waveguide. 
The waveguide beam illuminates a fixed mirror which deflects the power downward onto a steerable mirror. The vertical axis of rotation allows the beam to be aimed toroidally and injected through a slotted blanket/shield module. Since the elevation of the waveguide and steerable optic differ, shielding can be staggered so that no line-of-sight exists between the first wall and the bioshield (Fig. 1).

The shield/blanket plug forms a separate assembly (Fig. 2). An advantage of this arrangement is that there are no ECRF components attached to the blanket or backplate. Thus no special compensation for the relative motion of the blanket/shield with respect to the vacuum vessel is required and no forces are transmitted from one to the other. The modules forming the shield/blanket plug use a design analogous to the breeder blanket modules in order to provide cooling to the inner surfaces of the slots.

The mirror shield block, containing the injection hardware and shielding for the magnets and pit area, is located within the port. The plasma facing components are located a minimum of $0.8 \mathrm{~m}$ from the plasma.

All components are contained within the port; there are no vacuum vessel extensions.

The SU\&WC systems follow a similar design with the exceptions that the angle of injection is fixed rather than variable.

\subsection{Analysis}

The plasma-facing steerable optics are mechanically and thermally the most stressed elements of the transmission system. Thermal loads are dominated by Ohmic RF dissipation. Conservative assumptions (Be coating, fully E-plane polarized wave, $1 \mathrm{MW}$ incident, Gaussian distribution) result in a peak heat flux of $3.5 \mathrm{MW} / \mathrm{m}^{2}$. Thermal modeling shows that this heat load can be accommodated with the available blanket thermo-hydraulic system ( 140 ${ }^{\circ} \mathrm{C}$ inlet temperature, $5 \mathrm{~m} / \mathrm{s}$ flow velocity, 4 $\mathrm{MPa}$ pressure, $8 \mathrm{~mm}$ diameter thin wall $\mathrm{SS}$ tube).

An electromagnetic analysis has been performed for a typical optic consisting of a SS body and $5 \mathrm{~mm}$ thick copper reflector inclined

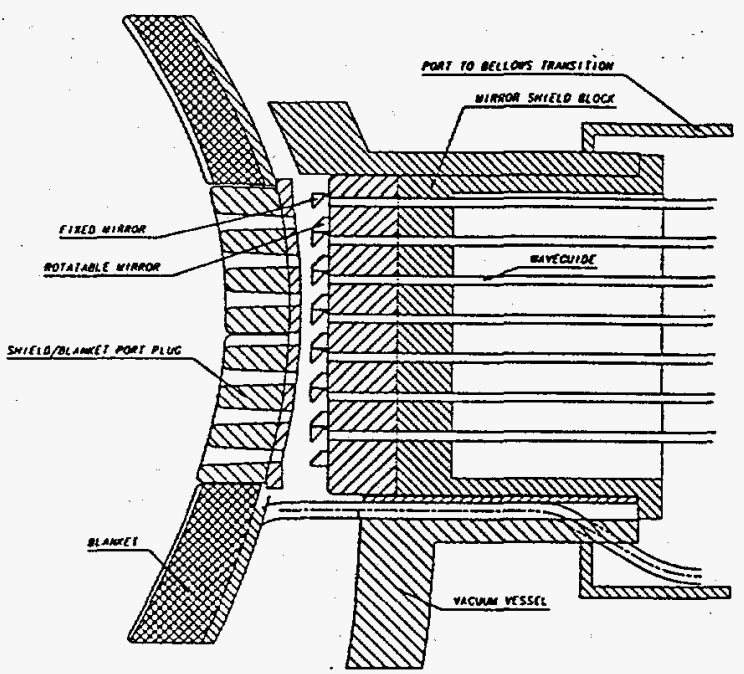

Fig. 1. Elevation view of the ECRF injection system.

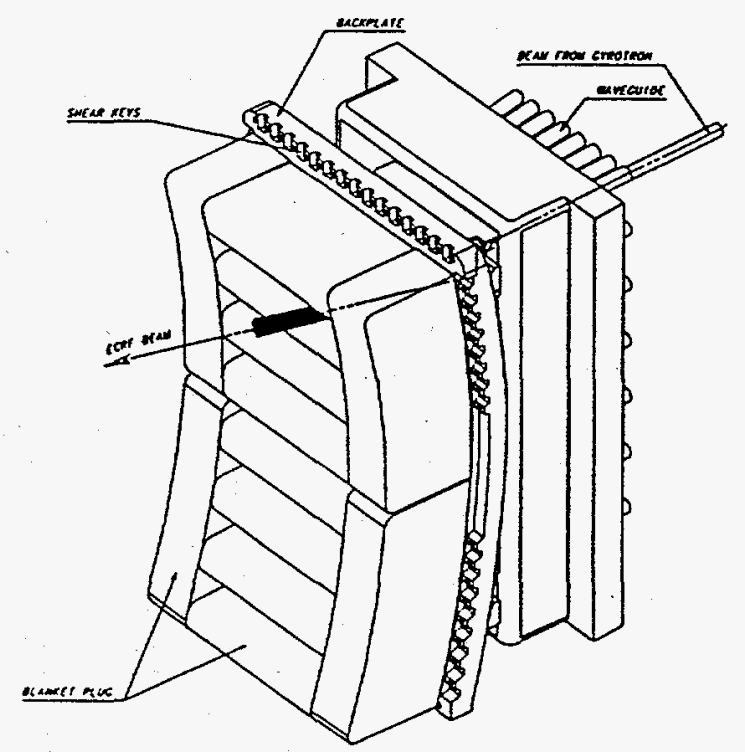

Fig. 2. Shield/blanket plug and mirror shield block for ECRF system.

at $45^{\circ}$ to a vertical magnetic field. The peak forces during a centered disruption are found to be negligible. An upper bound on the induced torque is $200 \mathrm{~N}-\mathrm{m}$ (the analysis did not model the cooling tubes and assumed room temperature copper). At this level, the load is supportable within allowable stresses. 
Improved modeling is expected to show a reduction in the torque by at least a factor 8 .

The shield/blanket plug reduces the nuclear heating and particle fluxes at the location of the mirror block by a factor of $\sim 10$ from that at the first wall. As a consequence, bare SS can be used; no Be cladding is needed. This greatly simplifies the design and fabrication of the mirror shield block. With the present design, the magnets and pit area are adequately shielded by the port module.

\section{ICRF SYSTEM}

\subsection{ICRF Design Features}

The ITER ICRF system has evolved from an in-blanket to an in-port concept, which lowers the impact to the blanket and allows simpler maintenance. The design changes have not significantly modified the operating scenarios. The principal heating scheme operates at $2 \Omega_{\mathrm{T}}=$ $\Omega_{\mathrm{He} 3}$ resonance, $\left(57 \mathrm{MHz}\right.$ at full $\mathrm{B}_{\mathrm{T}}$ ) with $\Omega_{\mathrm{D}}$ ( $42 \mathrm{MHz}$ at full $B_{\mathrm{T}}$ ) as an alternative. Fast wave current drive is in the frequency window between $2 \Omega_{\mathrm{T}}$ and $\Omega_{\mathrm{He}}$, where electron absorption is high. A maximum $C D$ efficiency $\eta=$ $0.15-0.20 \times 10^{20} \mathrm{~A} / \mathrm{W}-\mathrm{m}^{2}$ is predicted at 62.5 $\mathrm{MHz}$. Operation at lower $\mathrm{B}_{\mathrm{T}}$ is obtained by lowering the operating frequency, which can be varied in the range $40-70 \mathrm{MHz}$.

The ICRF system uses four antenna arrays located in adjacent mid-plane ports which are within the torus vacuum and tritium containment boundary. A nominal power of 2 $\mathrm{MW} /$ strap (or a total of $64 \mathrm{MW}$ ) is available. The maximum operating voltage is dependent on plasma coupling (typically $3 \Omega / \mathrm{m}$ ). Present estimates show that in unfavorable conditions, a total $50 \mathrm{MW}$ can be applied at an operating voltage $<42 \mathrm{kV}$.

\subsection{The Array Assembly}

An array consists of four similar modules stacked together between two side cover plates. Each module is a complete subsystem and includes a support case, a Faraday shield (FS), and two current straps (Fig. 3). The module case supports the current straps and the FS provides nuclear shielding and mechanical support. The cover plates protect the two free sides of the module stack and the FS cooling manifolds. They also provide the mechanical interface to the array main flange which is mechanically joined to the back plate. The ICRF array is electrically and mechanically attached to the blanket backplate by means of a bolted main flange, and to the vacuum vessel in order to accommodate differential thermal expansion and mechanical deformations between the blanket and vacuum vessel (VV). This arrangement also minimizes the mechanical loads applied by the plasma disruption currents to both back plate and array assembly.

The current strap is a U-shaped conductor folding horizontally in the port, with the central part parallel to the plasma magnetic surfaces, and recessed $\sim 2 \mathrm{~cm}$ from the transverse FS elements. The horizontal stubs mechanically support the vertical section and the pre-tuning components. The FS faces the plasma in front of the Current Straps and consists of a set of tilted $\left(16^{\circ}\right)$ elements. The feeder is asymmetrically connected close to the center of symmetry of the strap, at a point where the capacitive admittance of the long section is compensated by the inductive admittance of the short one. A resonant $\lambda / 2$ double loop antenna results, whose electrical length can be adjusted to different frequencies using the pre-tuning stubs. The (resistive) input impedance is matched to the actual plasma loading.

An important design issue is the array sensitivity to plasma edge density fluctuations (such as those due to ELMs), which cause fast variations in the antenna coupling and may reduce the RF power flow. The proposed pretuned antenna design provides the maximum tolerance to such variations. Computations show that, once pre-matched to a given frequency, plasma load variations in the range 2 to $8 \mathrm{~W}$, (or the whole range expected in ITER operation) can be accepted with input VSWR variations $<2$. The array pre-tuning requires small mechanical adjustments of the strap's electrical length whenever the operating 
frequency is changed. Practical methods to perform these adjustments are being developed.

All array components are cooled by forced circulation of pressurized water entering the central conductor of the bottom feeder and exiting in the central conductor of the top feeder.

\subsection{ICRF Wave Transmission}

The antenna feeders are connected to the pressurized main transmission lines by coaxial Vacuum Transmission Lines (VTLs). The vacuum / tritium boundary is provided by a double ceramic window at the VV main flange. The VTL successively passes through the VV port, the main VV port flange, the cryostat extension, and exits through the cryostat port.

The VTLs are pumped by getter pumps to maintain a specified base pressure independent of the torus vacuum conditions $\left(P_{\text {base }}<10^{-6}\right.$ $\mathrm{Pa}$ ). In the VTL, the inner conductor is used as a coolant duct for the array components and is positioned and supported by special all-metal wide band coaxial supports, based on a quasiresonant ridged wave guide concept, which allows a direct coolant transfer from inner to outer conductor.

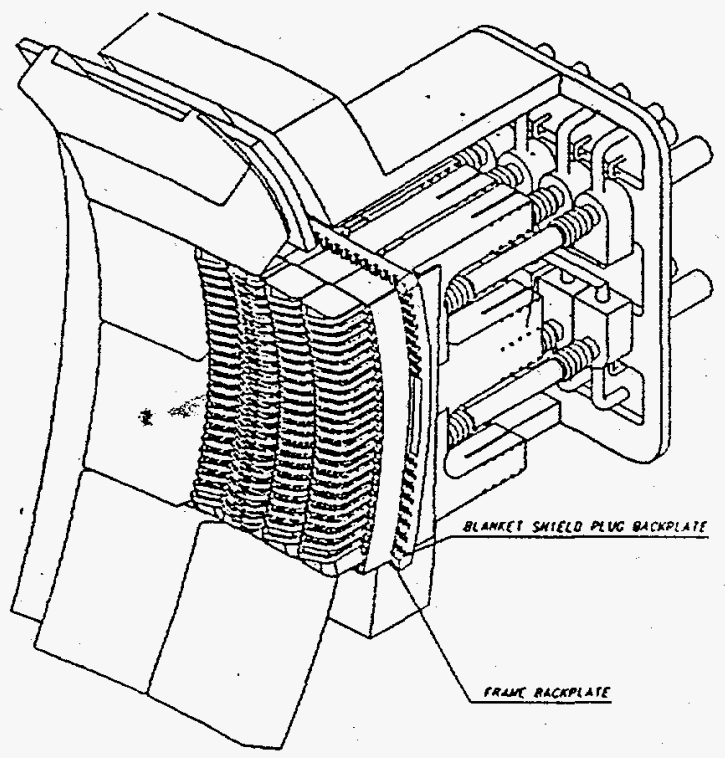

Fig. 3. ICRF Array module without FS.
The ICRF array provides neutron shielding of ex-vessel components. 3D calculations show that the maximum heating rates in the toroidal coils are in the range $0.10-0.33$ of the maximum allowed for both the steel and winding pack. Neutron and gamma fluxes at the location of the ceramic window $\left(1.8 \times 10^{16} \mathrm{n} / \mathrm{m}^{2}\right.$-sec) would not cause significant dielectric degradation in $\mathrm{BeO}$ ceramic windows, although $\mathrm{Al}_{2} \mathrm{O}_{3}$ windows would be near their end-of-life at the end of the BPP.

\subsection{Construction}

The array case can be built by Hot Iso-static Pressing (HIPing) of SS powders or by welding forged sections. A third and cheaper method is by casting austenitic gray iron inside a welded SS bag, containing the grid of cooling pipes. The current strap can also be of SS welded construction. The feeder and two horizontal arms are cylindrical and can be built from thick seamless pipes. The central part is curved with a rectangular hollow coolant channel.

The FS elements are a composite construction of SS and copper and have differing complex 3D shapes. Although the HIPing of dispersion strengthened copper powders together with SS pipes may be a better method of fabrication, the high number of molds required and the close tolerances may prevent the application of this method. The conductors can alternatively be produced from rectangular extruded bars of precipitation hardened copper alloy $(\mathrm{CuCr} \mathrm{Zr})$ drilled and lined with thin SS pipes.

\section{ACKNOWLEDGMENT}

This report was prepared as an account of work performed within the ITER Joint Central Team under the Agreement among the European Atomic Energy Community, the Government of Japan, the Government of the Russian Federation, and the Government of the United States of America on Co-operation in the Engineering Design Activities for the International Thermonuclear Experimental Reactor ("ITER EDA Agreement") under the auspices of the International Atomic Energy Agency (IAEA), and under the auspices of the U.S. Department of Energy by LLNL under contract W-7405-ENG.48. 